\title{
COMUNICAÇÃO
}

\section{PRIMEIRO RELATO DE Spalangia nigroaenea Curtis, 1839 (Hymenoptera: Pteromalidae) EM PUPAS DE Fannia pusio (Wiedemann, 1830) (Diptera: Fanniidae) NO BRASIL}

\author{
First report of Spalangia nigroaenea Curtis, 1839 (Hymenoptera: Pteromalidae) in pupae of \\ Fannia pusio (Wiedemann, 1830) (Diptera: Fanniidae) in Brazil
}

\author{
Carlos Henrique Marchiori'1, Vanessa Alves Alvarenga ${ }^{2}$
}

\begin{abstract}
RESUMO
Relata-se a primeira ocorrência do parasitóide Spalangia nigroaenea Curtis, 1839 (Hymenoptera: Pteromalidae) em pupas de Fannia pusio (Wiedemann, 1830) (Diptera: Fanniidae), no Brasil. Pupas de F. pusio foram coletadas em armadilhas utilizando-se fezes humanas como atrativo para os adultos. Obtiveram-se 10 pupas, das quais duas estavam parasitadas por S. nigroaenea, verificando-se uma porcentagem de parasitismo de $20,0 \%$.
\end{abstract}

Termos para indexação: Dípteros, himenópteros, parasitismo, ocorrência, novo registro.

\begin{abstract}
The first occurrence in Brazil of the parasitoid Spalangia nigroaenea Curtis, 1839 (Hymenoptera: Pteromalidae) in pupae of Fannia pusio (Wiedemann, 1830) (Diptera: Fanniidae) is reported. Pupae of $F$. pusio were collected in traps using human feces to attract the adults. Ten pupae were obtained, of which two were parasitized by S. nigroaenea, thus demonstrating a parasitism rate of $20.0 \%$.
\end{abstract}

Index terms: Dipterous, himenopterous, parasitism, occurrence, new register.

(Recebido em 18 de maio de 2006 e aprovado em 13 de novembro de 2007)

As moscas da família Fanniidae (Diptera) podem produzir miíases e atuar na veiculação de patógenos ao homem e aos animais, sendo responsáveis pela transmissão de mais de 100 espécies de microorganismos causadores de doenças como bactérias, protozoários e helmintos (GREENBERG, 1971). Na zona rural, podem acarretar diminuição da produção de ovos, doenças gastrointestinais e parasitoses nos animais, além de causar incômodo à população humana vizinha às criações (BERTI FILHO et al., 1996; MARICONI et al., 1999).

Os adultos de Fannia pusio (Wiedemann, 1830) (Diptera: Fanniidae) são frequientemente encontrados em ambientes modificados pelo homem, com suas larvas criando-se em matéria orgânica em decomposição (MARCHIORI \& PRADO, 1995, 1996; MARCHIORI et al., 2000a,b; PONT, 1977). Como possibilidade de controle desses dípteros podem ser utilizados determinados grupos de parasitóides.

Objetivou-se, neste trabalho, relatar a primeira ocorrência do parasitóide Spalangia nigroaenea Curtis,
1839 (Hymenoptera: Pteromalidae) em pupas de F. pusio, no Brasil.

$\mathrm{O}$ estudo foi conduzido em área de cerrado no Campus da Faculdade de Agronomia, em Itumbiara ( $\left.18^{\circ} 25^{\prime} \mathrm{S} ; 4^{\circ} 13^{\prime} \mathrm{W}\right)$, Goiás, Brasil, utilizando-se armadilhas "pitfall", indicadas para captura de insetos das ordens Diptera e Hymenoptera (MARCHIORI et al., 2001), tendo fezes humanas frescas como isca. Foram utilizadas cinco armadilhas distanciadas a 2 metros entre si e distribuídas aleatoriamente na área, substituindo-se as iscas a cada quinze dias. As pupas encontradas nas iscas foram separadas pelo método de flotação (MARCHIORI et al., 2000a) e, posteriormente, individualizadas em cápsulas de gelatina até a emergência das moscas e/ou dos parasitóides. As avaliações foram realizadas no período de janeiro a dezembro de 2005. A porcentagem de parasitismo foi calculada por meio do número de pupas parasitadas/número total de pupas obtidas x 100 .

Obtiveram-se 10 pupas de $F$. pusio coletadas em 15 de março e 30 de abril, das quais emergiram dois espécimes

1Biólogo, Doutor, Professor - Departamento de Ciências Biológicas - Centro Federal de Educação Tecnológica de Urutaí/UNED - Br 153, Km 633 - Zona Rural - Cx. P. 92 - 75650-000 - Morrinhos, GO - chmarchiori@yahoo.com.br

${ }^{2}$ Bióloga - Departamento de Ciências Biológicas - Instituto Luterano de Ensino Superior de Itumbiara/ILES-ULBRA - Avenida Beira Rio - Nova Aurora Cx. P. 23-T - 75500-000 - Itumbiara, GO - pesquisa.itb@ulbra.br 
de $S$. nigroaenea, provenientes daquelas coletadas no mês de abril, verificando-se uma porcentagem de parasitismo de $20,0 \%$, em razão, provavelmente, da sazonalidade intrínseca apresentada por essa espécie de parasitóide.

No Brasil, $S$. nigroaenea já havia sido coletada nos Estados de Mato Grosso, São Paulo e Minas Gerais em pupas de Musca domestica L., 1758 e Stomoxys calcitrans (L., 1758) (Diptera: Muscidae), provenientes de esterco bovino (SILVEIRA et al., 1989). Nos Estados Unidos, esse parasitóide foi encontrado em 14,0\% das pupas de Haematobia irritans (L., 1758) (Diptera: Muscidae) no Estado do Mississippi (COMBS \& HOELSCHER, 1969), em 3,0\% das pupas de $M$. domestica em fazendas de New York (SMITH \& RUTZ, 1991) e em 0,70\% das pupas de $S$. calcitrans, em fazendas do Missouri (SMITH et al., 1987).

Este trabalho registra a primeira ocorrência de $S$. nigroaenae como parasitóide de $F$. pusio no Brasil.

\section{REFERÊNCIAS BIBLIOGRÁFICAS}

BERTI FILHO, E.; THOMAZINI, M. J.; COSTA, V. A. Artrópodes benéficos associados ao esterco de galinhas poedeiras no Brasil. Revista de Agricultura, Piracicaba, v. 71, p. 273-286, 1996.

COMBS JUNIOR, R. L.; HOELSCHER, C. E. Hymenopterous pupal parasitoids found associated with horn fly in Northeast Mississippi. Journal of Economic Entomology, College Park, v. 62, p. 1234-1235, 1969.

GREENBERG, B. Flies and disease: ecology, classification and biotic association. New Jersey: Princeton University, 1971. $856 \mathrm{p}$.

MARCHIORI, C. H.; CASTRO, M. E. V.; PAIVA, T. C. G.; SILVA, C. G.; TEIXEIRA, F. F. Dípteros muscóides de importância médica e veterinária e seus parasitóides em Goiás. Arquivo Brasileiro de Medicina Veterinária e Zootecnia, Belo Horizonte, v. 52, p. 350-353, 2000a.

MARCHIORI, C. H.; PRADO, A. P. Longevidade e fecundidade de Fannia pusio (Wiedemann, 1830) (Diptera: Fanniidae) em laboratório. Revista Brasileira de Biologia, São Carlos, v. 55, p. 571-575, 1995.
MARCHIORI, C. H.; PRADO, A. P. Efeito da temperatura no desenvolvimento dos estágios imaturos de Fannia pusio (Wiedemann, 1830) (Diptera: Fanniidae) em laboratório. Revista Brasileira de Biologia, São Carlos, v. 56, p. 93-98, 1996.

MARCHIORI, C. H.; SILVA, C. G.; CALDAS, E. R.; ALMEIDA, K. G. S.; CARVALHO, S. A. Primeira ocorrência do parasitóide Nasonia vitripennis (Walker) (Hymenoptera: Pteromalidae) em pupas de Peckia chrysostoma (Wiedemann) (Diptera: Sarcophagidae). Arquivo do Instituto Biológico, São Paulo, v. 68, p. 107109, 2001.

MARCHIORI, C. H.; SILVA, C. G.; CALDAS, E. R.; VIEIRA, C. I. S.; ALMEIDA, K. G. S.; TEIXEIRA, F. F.; LINHARES,

A. X. Dípteros muscóides associados com carcaça de suíno e seus parasitóides em área de pastagem e de mata em Goiás. Arquivo Brasileiro de Medicina Veterinária e Zootecnia, Belo Horizonte, p. 459-460, 2000b.

MARICONI, F. A. M.; GUIMARÃES, J. H.; BARROS FILHO, E. A mosca doméstica. Piracicaba: FEALQ, 1999. $135 \mathrm{p}$.

PONT, A. C. A revision of Australian Fanniidae (Diptera: Calyptratae). Australian Journal of Zoology, Sidney, v. 1, n. 51, p. 1-60, 1977.

SILVEIRA, G. A. R.; MADEIRA, N. G.; AZEREDO-ESPIN, A. M. L. Levantamento de microhimenóptera parasitóides de dípteros de importância médico-veterinária no Brasil. Memórias do Instituto Oswaldo Cruz, Rio de Janeiro, v. 84, p. 505-510, 1989.

SMITH, J. P.; HALL, R. D.; THOMAS, G. D. Field parasitism of the stable fly (Diptera: Muscidae). Annals of the Entomology Society of America, Lanham, v. 80, p. 391-397, 1987.

SMITH, L.; RUTZ, D. A. Seasonal and relative abundance of hymenopterous parasitoids attacking house fly pupae at dairy farms in Central New York. Environmental Entomology, Lanham, v. 20, p. 661-668, 1991. 